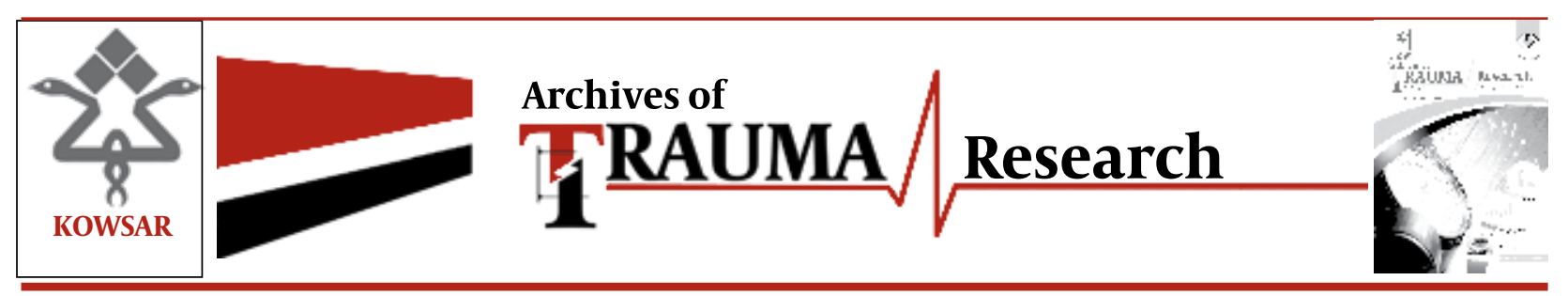

\title{
Pre-Hospital Trauma Care in Road Traffic Accidents in Kashan, Iran
}

\author{
Mohammad Paravar ${ }^{1}$, Mehrdad Hosseinpour ${ }^{2}$, Shayesteh Salehi ${ }^{1}$, Mahdi Mohammadza- \\ deh $^{2,}$, Abolfazl Shojaee ${ }^{2}$, Hossein Akbari ${ }^{2}$, Azadeh Sadat Mirzadeh ${ }^{2}$ \\ ${ }^{1}$ Faculty of Nursing and Midwifery, Khorasgan (Isfahan) Branch, Islamic Azad University, Isfahan, IR Iran \\ ${ }^{2}$ Trauma Research Center, Kashan University of Medical Sciences, Kashan, IR Iran \\ * Corresponding author: Mahdi Mohammadzadeh, Trauma Research Center, Kashan University of Medical Sciences, Kashan, IR Iran. Tel.: +98-3615550026, \\ Fax:+98-3615620634, E-mail:dmmzn58@gmail.com
}

\section{A B S T R A C T}

Background: Iran has one of the highest rates of road traffic accidents (RTAs) worldwide. Pre-hospital trauma care can help minimize many instances of traffic-related mortality and morbidity.

Objectives: The aim of this study was to assess the characteristics of pre-hospital care in patients who were injured in RTAs, admitted to hospital. The focus was mainly directed at evaluating pre-hospital trauma care provided in city streets and roads out of the city.

Patients and Methods: This retrospective study was carried out on all trauma patients, transported by the emergency medical service (EMS) system, who were admitted to Kashan Shahid-Beheshti hospital during the period from March 2011 to March 2012. The patients' demographic data, location of accident, damaged organs, mechanism of injury, injury severity, pre-hospital times (response, scene, transport), pre-hospital interventions and outcomes, were extracted from the data registry and analyzed through descriptive statistics using SPSS 18 software.

Results: Findings of this study showed that, $75 \%$ of RTAs occurred on city streets ( $\mathrm{n}=1251)$. Motor-car accidents were the most frequent mechanism of RTA on city streets $(n=525)(42 \%)$, while car rollover was the most frequent mechanism of RTA on roads out of the city ( $n=$ 155) (44.4\%). The mean pre-hospital time intervals ( $\mathrm{min}$ ); response, scene, and transport for all patients were $6.6 \pm 3.1,10.7 \pm 5$ and $13 \pm 9.8$, respectively. The mean pre-hospital time intervals (response, scene, transport) in roads out of the city were higher than those in city streets. There was a significant difference $(P=0.04)$ in the mortality rates due to RTAs between city streets $(n=46)$ and roads out of the city ( $n=32$ ). Conclusions: In comparison with road traffic accidents on city streets, trauma patients in RTAs on roads out of the city have longer prehospital time intervals and more severe injuries; therefore, this group needs more pre-hospital resuscitation interventions.

Keywords: Accidents; Pre-hospital Care; Traffic; Wounds and Injuries

Copyright ( @ 2013, Kashan University of Medical Sciences.; Published by Kowsar Corp.

Article type: Research Article; Received: 25 Oct 2012, Revised: 14 Nov 2012, Accepted: 19 Nov 2012; DOI: 10.5812/atr.8780

-Implication for health policy/practice/research/medical education:

Iran has one of the highest road traffic accident rates in the world. We hope that the results of this study can improve the knowledge of pre-hospital trauma, and road traffic accidents in Iran.

Please cite this paper as:

Paravar M, Hosseinpour M, Salehi S, Mohammadzadeh M, Shojaee A, Akbari H, et al. Pre-hospital Trauma Care in Road Traffic Accidents in Kashan, Iran. Arch Trauma Res. 2013;1(4):166-71. DOI:10.5812/atr.8780

Copyright @ 2013, Kashan University of Medical Sciences.; Published by Kowsar Corp.

This is an Open Access article distributed under the terms of the Creative Commons Attribution License (http://creativecommons.org/licenses/by/3.0), which permits unrestricted use, distribution, and reproduction in any medium, provided the original work is properly cited. 


\section{Background}

The issue of road traffic accidents (RTAs), with 50 million injuries annually, is a major public health problem in developing countries (1). Iran has the highest rate of RTAs worldwide (2). After cardio- and cerebrovascular diseases, RTAs are considered to be the third leading cause of mortality in Iran. Each year approximately 28000 people are killed and 800000 (1.1\% of the population) are injured on city streets and roads of Iran (2-4). Like many countries, the emergency medical service (EMS) is a system responsible for providing pre-hospital trauma care in Iran in 1977. In the EMS, emergency medical technicians (EMTs) are trained to provide basic life support (BLS) and advanced life support (ALS) for trauma patients. The US National Highway Traffic Safety Administration created the EMS-symbol or 'Star of Life' symbol which represents the six EMS functions for pre-hospital trauma care including; detection, reporting, response, on-scene care, care in transit and transfer to hospital $(5,6)$. The majority of RTA deaths in developing countries occur in the pre-hospital setting $(7,8)$. Studies in Iran have shown that about $60 \%$ of the deaths occurred at the crash scene or on the way to hospital (3). Pre-hospital care in RTAs increased dramatically form $7.5 \%$ to $60.4 \%$ during 2002-2011 in Iran (9, 10). To mitigate the consequences of RTAs, EMS capabilities in terms of human and physical resources have improved in recent years (11). In addition, improvements in pre-hospital care may decrease trauma mortality during the first few hours after injury, and it may also reduce the long-term mortality and morbidity rates due to RTAs $(7,12-14)$. Few studies have been done on pre-hospital trauma care for the injured people in Iran and those that have been conducted have mainly focused on evaluating pre-hospital trauma care provided in Tehran, which is a metropolitan city $(11,15,16)$, while no studies have been carried out in other regions in Iran, especially cities located on main roads out of the city. We hope that this study results in improving the knowledge of pre-hospital trauma care, especially in RTAs in Iran.

\section{Objectives}

This study was designed to describe the characteristics of patients, requiring pre-hospital care, which were injured in RTAs and admitted to hospital. The focus was mainly on evaluating pre-hospital trauma care provided on city streets and roads out of the city.

\section{Patients and Methods}

This retrospective study was performed on all trauma patients, conveyed by EMS, and admitted to hospital during March 2011 to March 2012. Data were extracted from a data bank of trauma research center and EMS registry data including; demographic data of patients, place of accident, damaged organs, mechanism, injury severity, prehospital times (response, scene, transport), pre-hospital interventions and outcomes. Patients who had injured resulted in immediate admission to hospital for two days or longer were included in the study and those who had died either at the scene or on route to the hospital excluded from the study. The pre-hospital time intervals were defined as the sum of the following time intervals including; response interval (time from alarm activation to arrival of the first responding vehicle on the scene) on-scene interval (time arrival of the first EMS response vehicle on the scene until leaving the scene) transport interval (time leaving the scene to the vehicle's arrival at the receiving hospital).

Injury severity was defined using a revised trauma score (RTS). The RTS was calculated using the following formula; Glasgow Coma Score (GCS), systolic blood pressure (SBP) and respiratory rate (RR). RTS ranged from 0.00 to 7.84. Variables were described by the number of cases and percentages for the categorical data, and as means and standard deviations for the numerical data. The pre-hospital time intervals and interventions were set as independent variables. Dependent variables were classified into two groups, city streets vs. roads out of the city. Associations were analyzed using $X^{2}$ tests. The statistical significance level was chosen as $5 \%(P=0.05)$.

\section{Results}

The mean age of the patients was $34.4 \pm 19.2$ years (age range, 2-94 years) and the male: female ratio was 4.7:1. The mechanisms of injury were; motorcycle (59.2\%), car (23.7\%), pedestrian (15.8\%) and bicycle (1.3\%). In total, $25 \%$ of trauma patients $(n=400)$ had more than two injured organs. Head and neck injuries were the most common (52\%) and injuries in the upper and lower extremities (49.7\%) stood in the second place. Only 3.1\% of motorcyclists had used a helmet, and $16.1 \%$ of car occupants had fastened their seat belt. The mean of the RTS in all patients was $7.46 \pm 0.86$. Table 1 shows the characteristics of trauma patients and pre-hospital care. The mean response time, at scene time, and transport time for all patients were $6.6 \pm 3.1,10.7 \pm 5$ and $13 \pm 9.8$, respectively. Intravenous (IV) access was established for all patients. Mean systolic blood pressure was $115.1 \pm 17.7 \mathrm{mmHg}$. Four hundred and eleven $(25.7 \%)$ patients were treated with IV fluids, and 344 patients (21.5\%) had a Glasgow Coma Score (GCS) of less than 13. Spinal protective devices (neck collar and long backboard) were used for $39 \%$ of the cases. Thirty-one patients underwent endotracheal intubation (ETI) for airway protection at the crash scene or on the way to the hospital. Cardiopulmonary resuscitation (CPR) was performed on three injured patients $(0.2 \%)$ at the accident scene. Mortality rate was $4.9 \%(n=78)$. 
Table 1. Characteristics of Trauma Patients and Pre-Hospital Care

\begin{tabular}{lll}
\hline Variable & Range & Mean \pm SD \\
\hline Age, $\mathbf{y}$ & $2-94$ & $34.4 \pm 19.2$ \\
\hline RTS $^{\text {a }}$ & $2.69-7.84$ & $7.46 \pm 0.86$ \\
\hline GCS $^{\text {a }}$ & $3-15$ & $13.7 \pm 2.5$ \\
\hline SBP, $^{\text {mmHg }}{ }^{\text {a }}$ & $60-200$ & $115.1 \pm 17.7$ \\
\hline DBP, $^{\text {mmHg }}{ }^{\text {a }}$ & $40-110$ & $73.1 \pm 9.8$ \\
\hline RR $^{\text {a }}$ & $5-30$ & $16.2 \pm 2.7$ \\
\hline PR $^{\text {a }}$ & $56-130$ & $81.8 \pm 9.9$ \\
\hline Response time, min $^{\text {On scene time, } \text { min }}$ & $1-36$ & $6.6 \pm 3.1$ \\
\hline Transport time, $^{\text {min }}$ & $3-40$ & $10.7 \pm 5$ \\
\hline Hospital stay & $2-120$ & $13 \pm 9.8$ \\
\hline
\end{tabular}

${ }^{a}$ Abbreviations: DBP, diastolic blood pressure; GCS, glasgow coma score; PR, pulse rate; RR, respiratory rate; RTS, revised trauma score; SBP, systolic blood pressure
Overall, $75.8 \%$ of RTAs occurred on city streets $(n=1251$ ) and the remainder occurred on roads out of the city. $\mathrm{Ta}$ ble 2 shows the characteristics of trauma patients on city streets and those on roads out of the city. According to the results in Table 2, there was no significant difference in the mean age of patients in city streets $(34.1 \pm 19.6)$ and roads $(35.5 \pm 17.8)$, while there was a significant difference in gender of the victims between the two groups of accidents (accidents on city streets and on roads out of the city) $(\mathrm{P}=0.008)$. Motor-car accident was the most frequent mechanism of RTA on city streets $(n=525)(42 \%)$, while car rollover was the most frequent mechanism of RTA on roads out of the city $(n=155)(44.4 \%)$. Head and neck injuries $(n=209)(60 \%)$ mostly occurred on roads out of the city, while the majority of upper and lower extremity injuries ( $\mathrm{n}=705)$ (56.4\%) occurred on city streets. There was a significant difference in the mortality rates between accidents on city streets $(n=46)$ and those on roads out of the city $(n=32)(P=0.04)$.

\begin{tabular}{|c|c|c|c|c|}
\hline Demographics & Total & City Streets & Roads Out of The City & PValue \\
\hline \multicolumn{5}{|l|}{ Gender, No. (\%) } \\
\hline Male & $1323(82.7)$ & $1033(85.2)$ & $290(75)$ & 0.008 \\
\hline Female & $277(17.3)$ & $180(14.8)$ & $97(25)$ & \\
\hline Age, y, Mean \pm SD & $34.4 \pm 19.2$ & $34.1 \pm 19.6$ & $35.5 \pm 17.8$ & 0.2 \\
\hline \multicolumn{5}{|l|}{ Age range, y, No. (\%) } \\
\hline Child (under 19) & $348(21.8)$ & $292(24.1)$ & $56(14.6)$ & 0.01 \\
\hline Adult $(20-59)$ & $1013(63.3)$ & $732(60.4)$ & $281(72.2)$ & 0.01 \\
\hline Old (over 60) & 239 (14.9) & $188(15.5)$ & $51(13.2)$ & 0.59 \\
\hline \multicolumn{5}{|c|}{ Mechanisms of injury, No. (\%) } \\
\hline Car-car & $187(11.7)$ & $115(9.5)$ & $72(19)$ & 0.004 \\
\hline Car rollover & $191(11.9)$ & $18(1.5)$ & $173(45)$ & $<0.001$ \\
\hline Motorcycle-car & $577(36.1)$ & $510(42)$ & $67(17)$ & $<0.001$ \\
\hline Motorcycle-motorcycle & $221(13.8)$ & $178(14.6)$ & $43(11)$ & 0.33 \\
\hline Motorcycle- rollover & $150(9.4)$ & $131(11)$ & $19(5)$ & 0.03 \\
\hline Pedestrian-car & $118(7.4)$ & $110(9)$ & $8(2)$ & 0.003 \\
\hline Pedestrian- motorcycle & $135(8.4)$ & $130(10.7)$ & $5(1)$ & $<0.001$ \\
\hline Bike & $21(1.3)$ & $21(1.7)$ & $0(0)$ & 0.2 \\
\hline \multicolumn{5}{|l|}{ Organ injuries, No. (\%) } \\
\hline Multiple & $408(25.5)$ & $300(24.7)$ & $108(27.9)$ & 0.51 \\
\hline Head and Neck & $832(52)$ & $612(50.4)$ & $220(56.8)$ & 0.18 \\
\hline Chest & $160(10)$ & $104(8.5)$ & $56(14.4)$ & 0.05 \\
\hline Abdomen & $120(7.5)$ & $80(6.5)$ & $40(10.3)$ & 0.15 \\
\hline Limb & $794(49.6)$ & $644(53)$ & $150(38.7)$ & 0.003 \\
\hline Pelvic & $104(6.5)$ & $77(6.3)$ & $27(6.9)$ & 0.85 \\
\hline Hospital stay, Mean \pm SD & $5.5 \pm 6.4$ & $5.2 \pm 5.6$ & $6.5 \pm 8.5$ & $<0.001$ \\
\hline Death, No.(\%) & $78(4.9)$ & $46(58.6)$ & $32(41.4)$ & 0.04 \\
\hline
\end{tabular}




\begin{tabular}{|c|c|c|c|}
\hline Variables & City Street & Roads Out of the City & Pvalue \\
\hline Systolic BP, Mean \pm SD $^{\text {a }}$ & $116.6 \pm 16.9$ & $111.9 \pm 19.9$ & 0.136 \\
\hline Diastolic BP, Mean \pm SD $^{\text {a }}$ & $73.5 \pm 9.4$ & $72.1 \pm 11.3$ & 0.04 \\
\hline Heart rate, bpm, Mean \pm SD & $81 \pm 9.1$ & $84.3 \pm 11.8$ & $<0.001$ \\
\hline Respiratory rate, Mean \pm SD & $16.3 \pm 2.5$ & $16.6 \pm 3.3$ & $<0.001$ \\
\hline Glasgow Coma Score, Mean \pm SD & $13.9 \pm 2.3$ & $13.1 \pm 3.1$ & $<0.001$ \\
\hline Trauma Score, RTS, Mean \pm SD & $7.53 \pm 0.75$ & $7.25 \pm 1.1$ & $<0.001$ \\
\hline IV fluid, No. (\%) ${ }^{\mathrm{a}}$ & $274(22.6)$ & $137(35.4)$ & 0.003 \\
\hline Intubation, No. (\%) & $51(4.2)$ & $32(8.3)$ & 0.08 \\
\hline Response time, min, Mean \pm SD & $5.8 \pm 1.9$ & $8.9 \pm 4.5$ & $<0.001$ \\
\hline On scene time, min, Mean \pm SD & $9.7 \pm 3.5$ & $13.8 \pm 7.2$ & $<0.001$ \\
\hline Transport time, min, Mean \pm SD & $9.6 \pm 4.9$ & $23.7 \pm 23.8$ & $<0.001$ \\
\hline
\end{tabular}

a Abbreviations: BP, blood pressure; IV, intravenous; RTS, revised trauma score

The roads out of the city had significant RTS $\leq 4$ (OR: 2.67, 95\%, CI 0.8 - 8.89), ETI (OR: 2.07, 95\%, CI $0.98-4.37$ ) and IV fluid administration (OR: 1.8, 95\%, CI 1.2 - 2.8). Table 3 shows the pre-hospital time intervals and care administered on city streets and roads out of the city. Obviously, the mean pre-hospital time intervals (response, scene, transport) in roads out of the city were higher than those on city streets.

\section{Discussion}

RTAs in Iran and other developing countries are the leading cause of morbidity and mortality in young men (under 40 years). In our study, the Mean \pm SD age of patients was less than 40 years. This finding was also reported by Roudsari et al. $(17,18)$, Nazari et al. (19) in Iran and Durak et al. in Turkey (20). Motorcycles were responsible for the majority of road traffic crashes in our study accounting for $59.2 \%$ of cases. The findings of this study were in accordance with those reported by Markogiannakis et al. in Greece (21), Chalya et al. in Tanzania (22) and Fazel et al. in Iran (9). In addition, motorcycle events are the most common injury mechanism on city roads. Approximately one half of the motorcyclists had a traumatic brain injury (TBI). There was a significant relationship between head injury and death $(\mathrm{P}=0.000)$. In our study, $90 \%$ of the motorcyclists who died had sustained a head trauma. Only 3.1\% of motorcyclists had used a helmet for protection. On the other hand, car mishaps were the most common injury mechanism on roads out of the city; however, only $16.1 \%$ of car occupants had fastened their seat belt for injury protection. The helmet is a successful device for preventing injuries among motorcyclists and it reduces the fatal and serious head injuries between $20 \%$ and $45 \%$ (23). The Peden et al. study (1) showed that the use of a protective device (helmet, seat belt) resulted in a $40 \%$ - 50\% total injury reduction. Unfortunately, despite law enforcement of using injury protective devices, seat belt and helmet use was rare (18), and needs mandatory legislation. The mean of RTS in all patients was $(7.46 \pm 0.86)$, and this was similar to the study of Markogiannakis et al. in Greece (21). The RTS was an important predictive scale for survival (20). Although $75.8 \%$ of all RTAs occurred on city streets, trauma severity and mortality rate in traffic accidents occurred on roads out of the city were higher than those on city street. Results of the study were in accordance with those of Nazar et al. study (19). Roads out of the city included; highways, freeways and roads with high speed vehicles that resulted in serious injuries and death. According to the comprehensive coverage guidelines of Iranian EMS, response time must be less than eight minutes in $80 \%$ of EMS operations on city streets and less than 15 minutes in $80 \%$ of EMS operations on roads out of the city (24). Response time in our study was 6.6 minutes which is satisfactory. The mean of the pre-hospital time intervals (response, at scene and transport) in accidents occurred on city street were significantly lower than those in accidents occurred on roads out of the city. The results of this study were in accordance with those of the Bigdeli et al. study (25). In the Gonzalez et al. study, they showed that a pre-hospital time increase resulted in higher mortality rates (26). Our findings were in accordance with those of the Gonzalez et al. study. Fifty eight patients (9.7\%) had a SBP less than 90 mmHg. A significant relationship was seen between SBP $\leq 90 \mathrm{mmHg}$ with death $(\mathrm{P}=0.000)$ and RTAs on roads out the city $(\mathrm{P}=0.02)$ in our study. The results of Edelman et al. study (27) showed that trauma patients with a SBP $\leq 109 \mathrm{mmHg}$ were at increased risk for morbidity and mortality following trauma. According to the results of Hasler et al. study (28), mortality rate was doubled in patients with SBP 90-109 mmHg, four-fold higher at 70 $89 \mathrm{mmHg}$ and 10 -fold higher at $<70 \mathrm{mmHg}$ compared to patients with SBP $110-129 \mathrm{mmHg}$. We suggest that all RTA trauma patients with a SBP less than $90 \mathrm{mmHg}$ should be considered as a special group requiring aggressive resus- 
citation with fluid administration. The mean GCS of the patients who underwent airway intubation was $5.8 \pm 1.8$. Although an intubation improves patient outcomes (29), they need more time to perform. Therefore, some studies have shown that patients intubated at the scene may have unrecognized episodes of hypoxia or hypo-tension, thus leading to poorer outcomes $(30,31)$. Based on NAEMT (32) in situations such as out of city roads, and suburban locations with longer transport times, intubation may be more beneficial than no intubation at all, even when done by a less experienced operator. Our study showed that there was a significant relationship between airway intubation and survival rate $(\mathrm{P}=0.003)$ in RTAs (city streets and roads out of the city). Moreover, our study suggests that all patients with severe head trauma (GCS $\leq 8$ ) should be intubated. In conclusion, trauma patients on roads out of the city have a longer pre-hospital care interval and they also have more severe injuries. Therefore, this group requires more pre-hospital resuscitation interventions (eg, IV fluids and ETI).

\section{Acknowledgements}

The authors wish to acknowledge Deputy of Research of Kashan University of Medical Sciences for its financial support in this study as part of a M.S thesis.

\section{Authors' Contribution}

Mohammad Paravar (Study design, article writing), Mehrdad Hosseinpour (study design), Shayesteh Salehi (study design), Mahdi Mohammadzadeh (Study design and article writing), Abolfazl Shojaee (data collection), Hossein Akbari (data analysis), Azadeh Sadat Mirzadeh (data collection).

\section{Financial Disclosure}

None declared.

\section{Funding Support}

This study has been funded and supported by deputy of research, Kashan University of Medical Sciences. Grant No: 9043.

\section{References}

1. Peden $\mathrm{M}$, Scurfield $\mathrm{R}$, Sleet $\mathrm{D}$, et al. World report on road traffic injury prevention.2004.

2. Bhalla K, Naghavi M, Shahraz S, Bartels D, Murray CJ. Building national estimates of the burden of road traffic injuries in developing countries from all available data sources: Iran. Inj Prev.2009;15(3):150-6

3. Naghavi M, Jafari N, Alaeddini F, Akbari ME. Injury Epidemiology caused by external cause of injury in the Islamic Republic of Iran.2005;

4. Road Traffic Injuries in Iran and their Prevention, A Worrying Picture. 2012.

5. "Star of Life": Emergency Medical Care Symbol-Background, Specifications, and Criteria.1995.

6. Sinthavalai R, Memongkol N, Patthanaprechawong J, Viriyanantavong J, Choosuk C. A study of distinctive model for pre-hospital
EMS in Thailand: Knowledge capture. World Academic Sci Eng Tech.2009;31:140-5.

7. Mock C, Arreola-Risa C, Quansah R. Strengthening care for injured persons in less developed countries: a case study of Ghana and Mexico. Inj Control Saf Promot.2003;10(1-2):45-51.

8. Montazeri A. Road-traffic-related mortality in Iran: a descriptive study. Pub Health.2004;118(2):110-3.

9. Fazel M, Fakharian E, Mahdian M, Mohammadzadeh M, Salehfard L, Ramezani M. Demographic Profiles of Adult Trauma During a 5 Year Period (2007-2011) in Kashan, IR Iran. Arch Trauma Res.2012;1(2):1-4.

10. Mohammad FI. Epidemiology of road traffic accidents leading death in Tehran province during 1999. Sci J Kurdistan Uni Med Sci.2002;23(6):35-40.

11. Khorasani-Zavareh D, Khankeh HR, Mohammadi R, Laflamme L, Bikmoradi A, Haglund BJ. Post-crash management of road traffic injury victims in Iran. Stakeholders' views on current barriers and potential facilitators. BMC Emerg Med.2009;9:8.

12. Demetriades D, Kimbrell B, Salim A, Velmahos G, Rhee P, Preston C, et al. Trauma deaths in a mature urban trauma system: is "trimodal" distribution a valid concept? J Am Coll Surg.2005;201(3):343-8.

13. Roudsari BS, Nathens AB, Arreola-Risa C, Cameron P, Civil I, Grigoriou G, et al. Emergency Medical Service(EMS) systems in developed and developing countries. Injury.2007;38(9):1001-13.

14. Sasser S, Varghese M, Kellermann A, Lormand JD. Prehospital trau ma care systems.2005

15. Modaghegh MH, Roudsari BS, Sajadehchi A. Prehospital trauma care in Tehran: potential areas for improvement. Prehosp Emerg Care.2002;6(2):218-23.

16. Ahmadi Amoli H, Tavakoli H, Khashayar P, Panahi F, Alavi Moghaddam M, Ahmadi Amoli M. The Efficacy of Pre-Hospital Care in Traumatic Patients referred to Emergency Ward of "Sina Hospital" between September 2003 and September 2004. Pajoohandeh J.2008;13(3):203-11.

17. Rasouli MR, Nouri M,Zarei MR, Saadat S, Rahimi-Movaghar V.Comparison of road traffic fatalities and injuries in Iran with other countries. Chinese JTraumatol.2008;11(3):131-4.

18. Roudsari BS, Sharzei K, Zargar M. Sex and age distribution in transport-related injuries in Tehran. Accident Analy Prevent.2004;36(3):391-8

19. Nazari R, Bijani A, Haji Hosseini F, Hojati H. Mortality and injury severity in the accident victims referred to the Hefdah Shahrivar hospital of Amol. J Babol Univ Med Sci.2011;13(1).

20. Durak D, Fedakar R, Turkmen N, Akgoz S, Baduroglu E. Road traffic collisions in Bursa, Turkey, during 2003, 2004 and 2005. In jury.2008;39(5):547-53.

21. Markogiannakis H, Sanidas E, Messaris E, Koutentakis D, Alpantaki $\mathrm{K}$, Kafetzakis A, et al. Motor vehicle trauma: analysis of injury profiles by road-user category. Emerg Med J.2006;23(1):27-31.

22. Chalya PL, Mabula JB, Dass RM, Mbelenge N, Ngayomela IH, Chandika $\mathrm{AB}$, et al. Injury characteristics and outcome of road traffic crash victims at Bugando Medical Centre in Northwestern Tanzania.J Trauma Manag Outcomes.2012;6(1):1.

23. Servadei F, Begliomini C, Gardini E, Giustini M, Taggi F, Kraus J. Ef fect of Italy's motorcycle helmet law on traumatic brain injuries. Inj Prev.2003;9(3):257-60.

24. Bahadori M, Nasiripur A, Tofighi S, Gohari M. Emergency medical services in Iran. Aust Med J.2010;3(6):335-9.

25. Bigdeli M, Khorasani-Zavareh D, Mohammadi R. Pre-hospital care time intervals among victims of road traffic injuries in Iran. A cross-sectional study. BMC Public Health.2010;10:406.

26. Gonzalez RP, Cummings GR, Phelan HA, Mulekar MS, Rodning CB Does increased emergency medical services prehospital time af fect patient mortality in rural motor vehicle crashes? A statewide analysis. Am J Surg.2009;197(1):30-4.

27. Edelman DA, White MT, Tyburski JG, Wilson RF. Post-traumatic hypotension: should systolic blood pressure of 90-109 $\mathrm{mmHg}$ be included? Shock.2007;27(2):134-8.

28. Hasler RM, Nuesch E, Juni P, Bouamra O, Exadaktylos AK, Lecky F. Systolic blood pressure below $110 \mathrm{~mm} \mathrm{Hg}$ is associated with increased mortality in blunt major trauma patients: multicentre cohort study. Resuscitation.2011;82(9):1202-7.

29. Winchell RJ, Hoyt DB. Endotracheal intubation in the field 
improves survival in patients with severe head injury. Trauma Research and Education Foundation of San Diego. Arch Surg.1997;132(6):592-7.

30. Davis DP, Peay J, Sise MJ, Vilke GM, Kennedy F, Eastman AB, et al. The impact of prehospital endotracheal intubation on outcome in moderate to severe traumatic brain injury. $J$ Trau- ma.2005;58(5):933-9.

31. Dunford JV, Davis DP, Ochs M, Doney M, Hoyt DB. Incidence of transient hypoxia and pulse rate reactivity during paramedic rapid sequence intubation. Ann Emer Med.2003;42(6):721-8.

32. NAEMT, McSwain N, Salomone J. PHTLS textbook for course student.2010;236. 